\title{
Análise cientométrica dos estudos bibliométricos publicados em periódicos da área de biblioteconomia e ciência da informação (1990-2005)
}

\section{Raymundo das Neves Machado}

\begin{abstract}
Professor do Departamento de Fundamentos e Processos Informacionais; Instituto de Ciência da Informação/UFBA; Mestre em Biblioteconomia/PUC-Campinas
\end{abstract}

Este estudo tem como objetivo analisar a temática em bibliometria vinculada em cinco periódicos nacionais, correspondendo ao período de 1990 a 2005, nos aspectos de procedência geográfica, evolução cronológica e orientação temática. Como método foi utilizado o quantitativo-descritivo, tendo como material de análise os artigos publicados nos periódicos: Ciência da Informação, Transinformação, Perspectivas em Ciência da Informação, DataGramaZero - Revista de Ciência da Informação e Revista da Escola de Biblioteconomia da UFMG. A amostra compreendeu 21 artigos escritos por autores brasileiros pertencentes a instituições sediadas no Brasil. Os resultados sugere que a produção em bibliometria publicada em artigos, em um período de 16 anos, ou seja, de 1990 a 2005, apresenta-se de forma assimétrica, variando entre o mínimo de um e o máximo de seis artigos/ano, sendo a Revista Ciência da Informação a de maior publicação, ou seja, publicou $71,4 \%$ dos artigos, mais que $50 \%$ do total, seguida pela Transinformação e Revista da Escola de Biblioteconomia da UFMG. Uma característica desta produção é a natureza dos autores, quer dizer, há predomínio da autoria única. No entanto, não há grandes produtores em bibliometria $A$ análise de citação, modalidade de estudo bibliométrico, está de certa forma impulsionando a área neste início de século, enfatizando os estudos na área de bibliometria.

Palavras-Chave: Bibliometria; Bibliometria - Produção científica - Brasil. 


\title{
Scientometric analysis of bibliometric studies published in brazilian library and information science journals (1990-2005)
}

\begin{abstract}
The aim of this study was to analyze the theme "bibliometric studies" published on five Brazilian journals, from 1990 to 2005, particularly the aspects of geographic origin, chronological evolution and thematic orientation. The methodology used was the quantitative-description analysis, using articles published on the following journals: Ciência da Informação, Transinformação, Perspectivas em Ciência da Informação, DataGramaZero Revista de Ciência da Informação, Revista da Escola de Biblioteconomia da UFMG. Twenty-one articles were used as the sample. They were written by Brazilian authors from Brazilian academic institutions. The results point out that the theme bibliometrics published in articles published over the period of 16 years (1990 to 2005) was presented in anti-symmetrical form, varying between the minimum of one to a maximum of six articles/year; Ciência da Informação was the journal with the greatest number of articles (71.4\%) followed by Transinformação and Revista da Escola de Biblioteconomia of UFMG. One characteristic of this production is the nature of the authors, with a predominance of single authorship, even though a large number of authors publishing about bibliometrics was not observed. The citation analysis thematics, one of the styles of bibliometric studies, is what promotes Brazilian studies on this area since the beginning of the 21st century.
\end{abstract}

Keywords: Bibliometric; Bibliometric - Scientific Production - Brazil.

Recebido em 04.12.2006 Aceito em 01.10.2007

\section{Introdução}

A atividade científica e tecnológica de um país requer um monitoramento, a fim de traçar-se seu estágio de desenvolvimento. Para Solla Price (1976), a ciência pode ser mensurada, ou seja, estudada nos seus aspectos quantitativos, gerando indicadores da performance de desenvolvimento científico e tecnológico. Desta forma, podemos observar 
o estágio atual do Brasil, em relação aos outros países, no ranking da ciência.

Observa Pivetta (2004), em um artigo intitulado "O salto quântico da ciência", que, "de 1990 para cá, triplicou o número de cientistas nas instituições de pesquisa, dobrou o percentual de artigos assinados por brasileiros em revistas internacionais indexadas e quintuplicou o total de novos doutores formados anualmente no país". Áreas como as ciências agrárias, a física, a ciência espacial, a microbiologia, as ciências das plantas e dos animais, a farmacologia e a matemática foram as que mais publicaram fora do país, dando maior visibilidade à ciência praticada no Brasil. É evidente que há mais pesquisadores qualificados fazendo ciência, apesar das inúmeras dificuldades pelas quais passam as universidades e os institutos de pesquisa do país.

A bibliometria, como área de estudo da ciência da informação, tem um papel relevante na análise da produção científica de um país, uma vez que seus indicadores retratam o grau de desenvolvimento de uma área do conhecimento.

Estudar a bibliometria praticada no Brasil, efetuando um recorte na produção científica gerada por pesquisadores brasileiros e vinculada em artigos publicados em periódicos nacionais, constitui a principal motivação para a realização deste artigo. Sendo assim, temos como objetivo estudar a temática em bibliometria vinculada em cinco periódicos nacionais, correspondendo ao período de 1990 a 2005 nos aspectos de: procedência geográfica, evolução cronológica e orientação temática. Para tanto, utilizamos a cientometria, aqui compreendida como um método "baseado em técnicas estatísticas, que tem como objetivo identificar e tratar as informações contidas nas publicações científicas e técnicas, disponíveis nos sistemas de informação..." (SANTOS, 2003, p. 136). Assim, "a cientometria compreende um conjunto de trabalhos consagrados à análise quantitativa da atividade de instigação científica e técnica" (BUFREM; PRATES, 2005, p. 13).

\section{Panorama dos estudos bibliométricos}

Cada vez mais as ciências sociais têm na matemática e na estatística uma aplicação para compreender certos fenômenos que constituem seus objetos de estudos. A utilização de métodos quantitativos tem como antecedente a doutrina elaborada por Augusto Comte, filósofo e matemático francês (1798-1857), denominada positivismo, que surgiu durante a segunda metade do século XIX. Para Comte "a ciência era o paradigma de todo conhecimento" (ALVES-MAZZOTTI; GEWANDSZNAJDER, 2001, p. 9).

Considerado como uma construção do saber, o positivismo tem como principais características o empirismo, a objetivação, a experimentação, a validade, as leis e a previsão. A ciência positivista é quantificativa, o que "permite se chegar às mesmas medidas, 
reproduzindo-se a experiência nas mesmas condições, concluir a validade dos resultados e generalizá-los" (LAVILLE; DIONNE, 1999, p. 28).

O processo de matematização das ciências sociais é denominado por Pérez Matos (2002) ciências métricas. Para Gregorio Chaviano (2004), esse processo é denominado técnicas métricas. Segundo ele, "a origem dos estudos métricos está marcada pelo surgimento da ciência da documentação, cujo propósito essencial foi [...] o controle do grau de quantidade de documentos existentes em diferentes áreas do saber".

Os estudos métricos relacionados com a informação, desenvolvidos no Brasil, e entre eles a bibliometria, datam da década de 70, quando da implantação do primeiro Mestrado em Ciência da Informação, pelo Instituto Brasileiro de Bibliografia e Documentação (IBBD), atual Instituto Brasileiro de Informação em Ciência e Tecnologia (IBICT), dando início à produção científica no terreno bibliométrico, proveniente dos primeiros trabalhos, frutos dos estudos e pesquisas dos mestrandos. No entanto, estudos envolvendo a quantificação da informação registrada datam de 1917, quando Cole e Eales traçaram como meta analisar o número de publicações na área de anatomia comparada no período de 1543 a 1860 . Em 1927, Gross e Gross quantificaram as referências no The Journal of the Americam Chemestry Society a fim de identificar as principais publicações na área de química (SANCHO, 1990).

Segundo Fonseca (1986) e Carrizo Sainero (2000), foi Paul Otlet que cunhou o termo bibliometria, em sua obra clássica Traité de Documentation, publicada em 1934, contendo as noções para a bibliometria. Para Otlet, a bibliometria é o meio de quantificar a ciência, utilizando-se da aplicação estatística nas fontes de informações. Foi Alan Pritchard que em 1969 popularizou a bibliometria como sendo um campo de estudo, no qual são utilizados modelos matemáticos e estatísticos para analisar a comunicação escrita numa determinada área.

Com a popularização do termo, muitos estudos foram sendo realizados, tornando a bibliometria um método de pesquisa que dá subsídios ao bibliotecário no gerenciamento dos serviços informacionais, como também proporciona maior conhecimento, por meio de seus indicadores, do desenvolvimento científico e tecnológico de um país.

$\mathrm{Na}$ década de 80, Urbirazagástegui Alavarado (1984) desenvolveu um amplo estudo, intitulado "A bibliometria no Brasil", cobrindo o período de 1972 a 1983, no qual analisou um total de 78 publicações distribuídas em: dissertações, teses, artigos de periódicos, comunicações apresentadas em congressos, monografias, folhetos e capítulos de livro, apresentando um quadro do estágio no momento dos estudos bibliométricos no país. Em sua conclusão, o autor observa a grande influência de professores estrangeiros que ministraram conteúdos em bibliometria, quando da implantação do mestrado no Brasil, tendo como grande precursor o Tefko Saracevic, também apontado por Pinheiro (2001) como o grande líder nesses estudos. A Lei de Bradford foi o grande tema de preferência dos autores brasileiros, principalmente no que tange à confecção de lista básica de periódicos em diversas áreas do 
conhecimento. Urbirazagástegui Alavarado (1984) e Pinheiro (2001) apontam Braga como pioneira nos estudos da bibliometria no país.

A ciência da informação tem como tema de sua agenda de pesquisa a produção científica, produto da comunicação científica, que proporciona a análise do estágio de desenvolvimento de uma determinada área do conhecimento humano. Para tanto recorre às disciplinas métricas (do grego metron), entre elas a bibliometria $e$, mais recentemente, a cientometria e a informetria. Por meio desses estudos, podemos mapear o avanço da ciência, conhecer as relações estabelecidas pelos pesquisadores, identificar núcleos de publicação de uma área, bem como a frente de pesquisa de um determinado campo.

O levantamento de indicadores, a fim de estudar a ciência, constitui um campo de estudo instrumental que possibilita estabelecer prognósticos e tendências a partir de determinados números de variáveis que, quando analisados, permitem o estabelecimento de indicadores para tomada de decisão.

Os indicadores em ciência e tecnologia vêm merecendo atenção por parte dos governos e da comunidade científica, uma vez que proporcionam uma maior visibilidade do desenvolvimento dos estados e municípios, no campo cientifico e tecnológico. Para tanto, estudos vêm sendo efetuados a fim de contribuir com instrumentos eficazes para tomada de decisão por partes dos governantes e das agências de fomento às pesquisas (MUGNAINI; JANNUZZI; QUONIAM, 2004; ROCHA, FERREIRA, 2004). Os estudos métricos, como um instrumental de pesquisa, contribuirão para uma análise da dinâmica no campo científico e tecnológico, o que corrobora com a observação feita por Solla Price (1976) de que a ciência pode ser mensurada, ou seja, estudada nos seus aspectos quantitativos, gerando indicadores da performance de desenvolvimento científico e tecnológico. Desta forma, podemos observar o estágio atual do Brasil em relação aos outros países no ranking da ciência.

\section{Material e método}

O método de investigação selecionado foi o quantitativo-descritivo, tendo como variáveis delineadas: produção anual; tipologia; categoria e filiação institucional dos autores; natureza e tipo de estudo; temática abordada nos artigos.

O material para o desenvolvimento desse estudo constitui-se dos artigos publicados, no período de 1990 a 2005, em periódicos da área de biblioteconomia e ciência da informação, discriminados no quadro abaixo: 
QUADRO 1 - Periódicos da Área de Biblioteconomia e Ciência da Informação, selecionados para o estudo

\begin{tabular}{|l|l|c|c|c|}
\hline \multicolumn{1}{|c|}{ Periódico } & \multicolumn{1}{|c|}{ Editor } & ISBN & $\begin{array}{c}\text { Periodicidade } \\
\text { Atual }\end{array}$ & Inicio \\
\hline $\begin{array}{l}\text { Ciência da } \\
\text { Informação }\end{array}$ & $\begin{array}{l}\text { Instituto Brasileiro de Informação } \\
\text { em Ciência e Tecnologia/IBICT }\end{array}$ & $\begin{array}{c}0100- \\
1965\end{array}$ & Quadrimestral & 1970 \\
\hline $\begin{array}{l}\text { DataGramaZero - } \\
\text { Revista de Ciência } \\
\text { da Informação }\end{array}$ & $\begin{array}{l}\text { Instituto de Adaptação e Inserção } \\
\text { na Sociedade da Informação }\end{array}$ & $\begin{array}{c}1517- \\
3801\end{array}$ & Bimensal & 1999 \\
\hline $\begin{array}{l}\text { Perspectiva em } \\
\text { Ciência da } \\
\text { Informação }\end{array}$ & Universidade Federal de Minas & $\begin{array}{c}1413- \\
9936\end{array}$ & Semestral & 1996 \\
\hline $\begin{array}{l}\text { Transinformação } \\
\text { Gerais }\end{array}$ & $\begin{array}{l}\text { Programa de Pós-Graduação } \\
\text { em Biblioteconomia da Pontifícia } \\
\text { Universidade Católica de }\end{array}$ & $\begin{array}{c}7866 \\
\text { Campinas. }\end{array}$ & Quadrimestral & 1989 \\
\hline $\begin{array}{l}\text { Revista da Escola de } \\
\text { Bibliotecon. UFMG. }\end{array}$ & $\begin{array}{l}\text { Universidade Federal de Minas } \\
\text { Gerais }\end{array}$ & $\begin{array}{c}0100- \\
0820\end{array}$ & Semestral & 1970 \\
\hline
\end{tabular}

Com relação ao material da pesquisa, deve-se ressaltar que, ao longo de sua existência, alguns periódicos sofreram algum tipo de alteração no que tange à periodicidade, bem como ao suporte. Assim, a Ciência da Informação, que era semestral até 1990, torna-se quadrimestral em 1991; a Revista da Escola de Biblioteconomia da UFMG passa a denominar-se, em 1996, Perspectivas em Ciência da Informação, mantendo a periodicidade semestral. Considerou-se a Perspectiva em Ciência da Informação como uma nova publicação e, pela contribuição e relevância para a área, optou-se por analisar a Revista da Escola de Biblioteconomia da UFMG, mesmo não sendo mais editada.

Para a seleção dos artigos foi elaborada uma lista de palavras-chave (APÊNDICE A), tomando como base os temas apresentados em um estudo desenvolvido por Urbirazagástegui Alavarado (1984). Verificou-se a presença dos termos no sumário, título do artigo e nas palavras-chave; já o resumo foi utilizado como elemento para subsidiar a tomada de decisão quanto à seleção dos artigos, se constituído em um elemento secundário. A etapa seguinte foi a adoção do critério de corte, isto é, foram considerados os artigos escritos por autores brasileiros vinculados a instituições sediadas no território nacional.

Os artigos identificados constituíram a amostra deste estudo, sendo examinados nas seguintes variáveis: áreas de atuação dos autores e vinculação institucional; distribuição dos autores segundo sua produtividade, ano dos trabalhos publicados, área geográfica dos autores; temática dos artigos. O material foi referenciado em formulários próprios, a fim de possibilitar sua localização e posterior análise, confeccionando para tanto um banco de dados no SPSS (Statistical Package for the Social Sciences) que, em conjunto com o software Microsoft Office Excel, foram utilizados na tabulação e sistematização dos dados. 
Para esse estudo, somente foram considerados os artigos, descartando-se os temas em debates, relatos de experiências e comunicações.

Para os métodos estatísticos, que inclui como hipóteses testar a associação entre as variáveis, teve como regra de decisão comparar o pvalor do teste (probabilidade de rejeitar a hipótese testada, dada que a mesma é verdadeira) com um nível de significância de 5\%. Quando o pvalor é menor que esse ponto de corte, o resultado é chamado de estatisticamente significante; nas outras situações como não significante. Por esta razão os testes são denominados testes de significância.

\section{Análise e discussão dos dados}

Formam analisados 147 números, distribuídos em 54 volumes, dos periódicos Ciência da Informação, Transinformação, Perspectivas em Ciência da Informação, DataGramaZero - Revista de Ciência da Informação e Revista da Escola de Biblioteconomia da UFMG, num total de 1.054 artigos, conforme TAB. 1 .

TABELA 1 - Material selecionado (1990-2005)

\begin{tabular}{l|c|c|c|c}
\hline \multicolumn{1}{c|}{ Periódico } & Volumes & Números & $\begin{array}{c}\text { Quantidade } \\
\text { de Artigo }\end{array}$ & $\begin{array}{c}\text { Artigo } \\
\text { Selecionado }\end{array}$ \\
\hline Ciência da Informação & 16 & 45 & 445 & 21 \\
\hline $\begin{array}{l}\text { DataGramaZero - Rev. Ciên. } \\
\text { Informação }\end{array}$ & 6 & 37 & 163 & 1 \\
\hline $\begin{array}{l}\text { Perspectivas em Ciência da } \\
\text { Informação }\end{array}$ & 10 & 22 & 180 & 3 \\
\hline R. Escola de Biblioteconomia de UFMG & 6 & 11 & 71 & 2 \\
\hline Transinformação & 16 & 32 & 195 & 4 \\
\hline Total & 54 & 147 & 1.054 & 31 \\
\hline
\end{tabular}

Vale ressaltar que um artigo não foi considerado no estudo, apesar de conter no elenco de descritores o termo "bibliometria", pois a leitura, na íntegra, do artigo, não identificou nenhuma relação com o termo. Até a finalização deste estudo o n. 3 do volume 34, 1995, da Ciência da Informação, não tinha sido editado. 


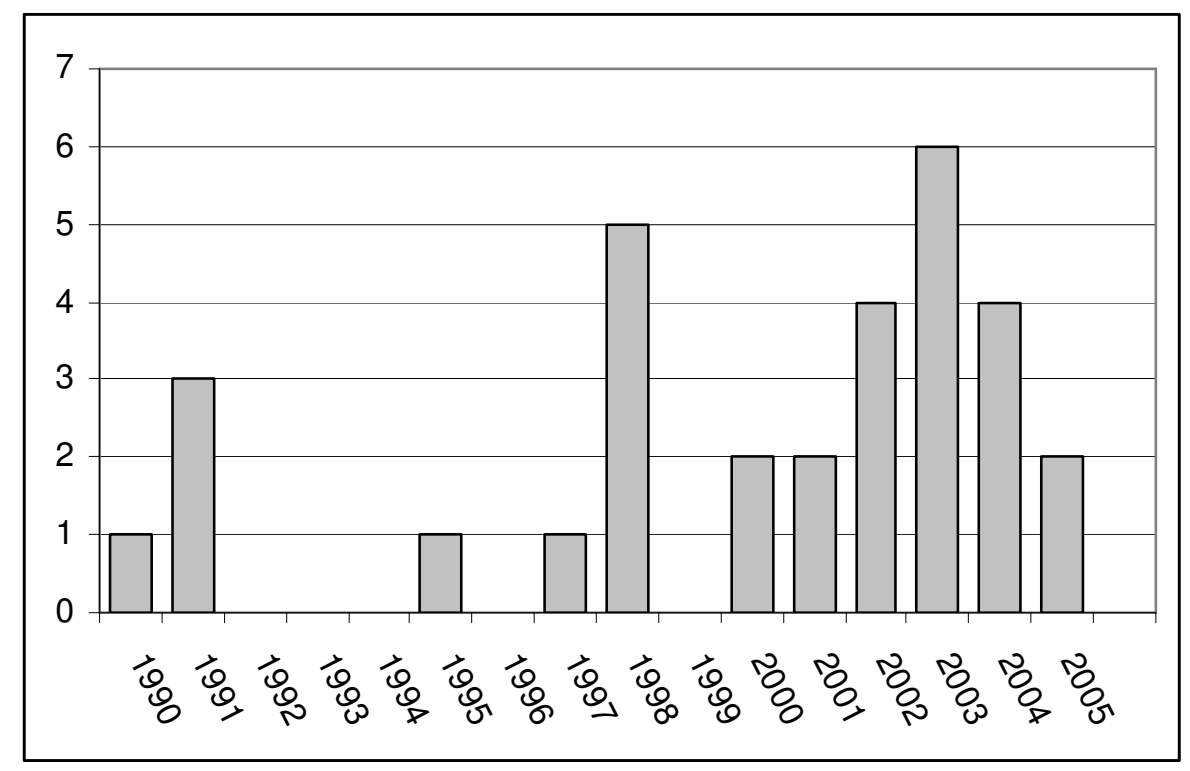

FIGURA 1 - Artigos Publicados no Período de 1990-2005.

A produção em bibliometria, publicada em artigos, no período de 16 anos (de 1990 a 2005), apresenta-se de forma assimétrica, variando entre o mínimo de um e o máximo de seis artigos, contabilizando um total de 31 trabalhos, tendo uma média igual a 1,94 artigo/ano, sendo os anos de 1998 e 2003 os de maiores expressões, ou seja, apresentaram o maior número de artigos publicados nos periódicos analisados. Entretanto, na década de 90, a produção não foi presente em todos os anos; o total de artigos foi da ordem de 11 unidades. Já em 2000, o quadro começa a apresentar mudanças: há produção contínua, num total de 20 artigos, variando de duas a seis publicações.

No entanto, uma parcela desta publicação são de autores estrangeiros, perfazendo um total de 32,2\%. Nosso objetivo foi analisar a produção nacional, isto é, autores que escreveram na temática bibliométrica pertencentes a instituições sediadas no território nacional ou que tenham desenvolvido estudos de pós-graduação fora do país. Assim sendo, 67,8\% do material levantado são de origem de autores brasileiros vinculados a instituições brasileiras e apenas um artigo é proveniente de uma tese defendida fora do país, o que totaliza 21 trabalhos com uma média de 1,31 artigo/ano. 
TABELA 2 - Estatística Descritiva da Produção

\begin{tabular}{l|c|c}
\hline \multirow{2}{*}{ Medidas } & \multicolumn{2}{c}{ Autores } \\
\cline { 2 - 3 } & Estrangeiros e Nacionais & Nacionais \\
\hline Média & 1,94 & 1,31 \\
\hline Desvio Padrão & 1,95 & 1,25 \\
\hline Mínimo de artigo & 1 & 1 \\
\hline Máximo de artigo & 6 & 4 \\
\hline Total de Artigos & 31 & 21 \\
\hline
\end{tabular}

Fazendo uma análise descritiva dos dados e separando a população estudada em autores "estrangeiros mais nacionais" e "nacionais" (TAB. 2), temos para o primeiro caso 31 artigos publicados por autores estrangeiros e nacionais, apresentando uma média de 1,94 artigo/ano com um desvio padrão de 1,95 artigo/ano, ou seja, maior do que a média; indicando uma considerável variabilidade de publicação anual de artigos, em relação à média dos artigos publicados por estrangeiros mais nacionais. Pode-se observar uma evidência de que esse valor foi em função dos artigos publicados por brasileiros, pois a média de artigos, publicados apenas por autores brasileiros, nesse mesmo período, num total de 21 trabalhos, foi de 1,31 artigo/ano, com um desvio padrão de 1,25 artigo/ano, constatando uma menor variabilidade em relação à publicação de artigos que leva em consideração autores estrangeiros.

Dos cinco periódicos analisados, apenas um não correspondeu ao critério de corte estabelecido para a seleção. Assim, a Revista Ciência da Informação publicou $71,4 \%$ dos artigos, ou seja, mais que $50 \%$, seguida pela Transinformação e Revista da Escola de Biblioteconomia da UFMG (TAB. 3).

TABELA 3 - Artigos publicados nos Periódicos da Área de Biblioteconomia e Ciência da Informação (1990-2005)

\begin{tabular}{l|c|c|c}
\hline \multicolumn{1}{c|}{ Revistas } & Quantidade & \% & \%c \\
\hline Ciência da Informação & 15 & 71,4 & 71,4 \\
\hline Transinformação & 3 & 14,3 & 85,7 \\
\hline Revista da Esc Bibliotecon UFMG & 2 & 9,5 & 95,2 \\
\hline Perspectivas em Ciência da Informação & 1 & 4,8 & 100 \\
\hline Total & 21 & 100 & \\
\hline
\end{tabular}

Vale ressaltar que o periódico Ciência da Informação tem um importante papel na área da biblioteconomia e da ciência da informação, uma vez que foi o primeiro veículo a divulgar os estudos e pesquisas desenvolvidos pelos alunos do curso de mestrado em ciência da informação, único do gênero no país na década de 70 , sendo também 0 
pioneiro a publicar os primeiros estudos/pesquisas no campo da bibliometria.

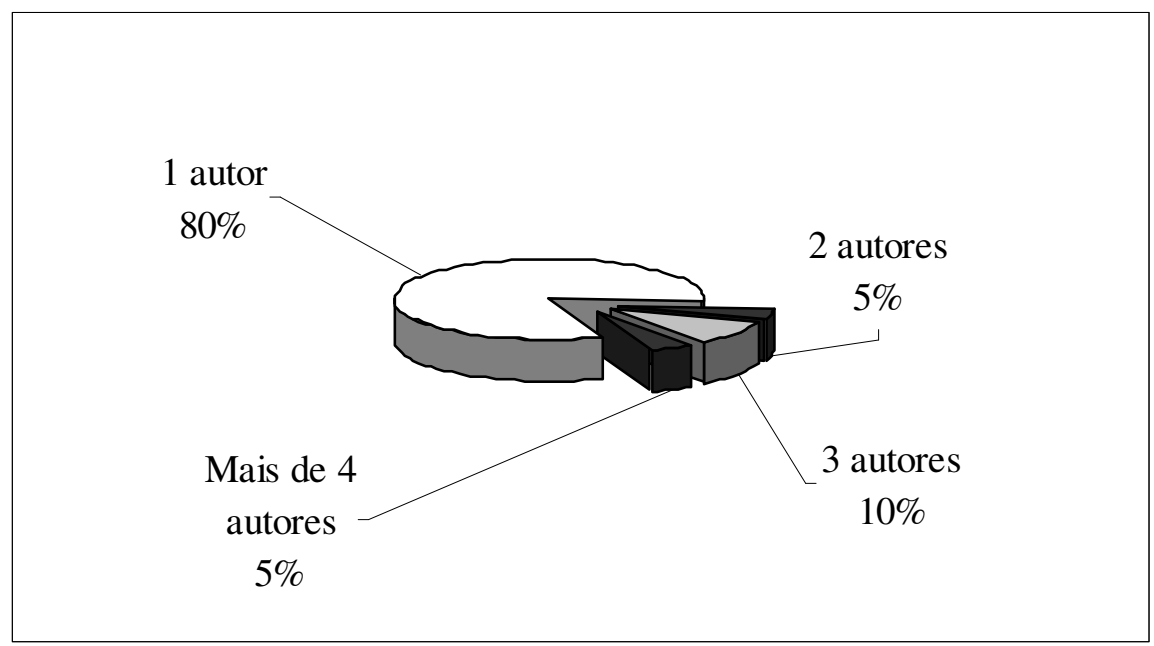

FIGURA 2 - Tipologia dos autores

Com relação à variável tipologia dos autores (TAB. 3), observa-se que $80 \%$ dos artigos são de autoria única; já a autoria múltipla, isto é, artigos assinados por mais de um autor, tem uma freqüência relativa de $20 \%$. Mueller e Pecegueiro (2001, p. 49), quando estudaram os artigos publicados na revista Ciência da Informação, observaram o mesmo dado, isto é, artigos com "autoria única predominam sobre a autoria em colaboração". Observa Meadows (1999, p. 109) que "a literatura gerada por pesquisas feitas em colaboração mostra diferenças importantes se comparadas com a produzida por pesquisadores que trabalham isoladamente". Para o autor, essa característica é bem mais peculiar das Humanidades do que das outras Ciências, principalmente das Exatas, embora a tendência na contemporaneidade seja a realização de trabalhos em equipes multidisciplinares.

Os trabalhos com co-autoria, em número de quatro, apresentaram diferentes níveis de colaboração, ou seja, intradepartamental (dois artigos), intrainstitucional (um artigo) e interinstitucional (um artigo).

TABELA 4 - Categoria dos Autores

\begin{tabular}{l|c|c|c}
\hline \multicolumn{1}{c|}{ Categoria } & Quantidade & \% & \%c \\
\hline Professor & 12 & 57,1 & 57,1 \\
\hline Bibliotecário & 3 & 14,3 & 71,4 \\
\hline Estatístico & 2 & 9,5 & 80,9 \\
\hline Coord. Grupo Pesquisa & 1 & 4,8 & 85,7 \\
\hline Não Informada & 3 & 14,3 & 100 \\
\hline Total & 21 & 100 & \\
\hline
\end{tabular}


A variável categoria dos autores foi mensurada, conforme TAB. 4. Assim sendo, mais de $50 \%$ dos autores são docentes vinculados a uma instituição de ensino superior. A produção em bibliometria encontra-se estreitamente ligada às atividades de ensino/pesquisa. Essa análise foi correlacionada à vinculação institucional (TAB. 5), onde foram identificadas 15 instituições, sendo a sua maioria universidade pública e privada (correspondendo a 73,33\%), com cursos de biblioteconomia e ciência da informação; com exceção de uma, sendo que o autor, embora proveniente da área da ciência da informação, hoje exerce suas atividades de ensino e pesquisa no campo da educação, aplicando os estudos bibliométricos na sua atual área de atuação. Quanto aos demais autores, $14,3 \%$ são bibliotecários, sendo um pertencente a uma unidade de ensino universitária e outro a uma instituição de pesquisa. O campo dos estudos e pesquisas em bibliometria não se resume somente às universidades, mas a outras organizações, como podemos observar na TAB. 5.

TABELA 5 - Vinculação Institucional dos Autores

\begin{tabular}{l|c|c}
\hline \multicolumn{1}{c|}{ Instituições } & Artigos & \% \\
\hline UFMG & 3 & 14,3 \\
\hline PUC-Campinas & 2 & 9,5 \\
\hline UFRGS & 2 & 9,5 \\
\hline BIREME & 2 & 9,5 \\
\hline UNIVALI & 2 & 9,5 \\
\hline Rede Ferroviária do Brasil SA & 1 & 4,8 \\
\hline USP & 1 & 4,8 \\
\hline UDESC & 1 & 4,8 \\
\hline UNB & 1 & 4,8 \\
\hline UFRJ & 1 & 4,8 \\
\hline UFPR & 1 & 4,8 \\
\hline UFES & 1 & 4,8 \\
\hline EMBRAPA AMAZÔNIA ORIENTAL & 1 & 4,8 \\
\hline UFSC & 1 & 4,8 \\
\hline IBICT & 1 & 4,8 \\
\hline Total & 21 & 100 \\
\hline
\end{tabular}

Vale ressaltar que foram mantidas a vinculação e a categoria dos autores, conforme consta em cada artigo analisado: é provável que haja alteração nessas variáveis.

Sendo a maioria dos autores docentes $(57,10 \%)$, foi possível mensurar também sua titulação. Para os autores que não informaram essa variável foi efetuada uma consulta à Plataforma Lattes, no entanto não foi encontrado nenhum registro; nesse caso o dado foi alocado na categoria de "não informada" (FIG. 3). 


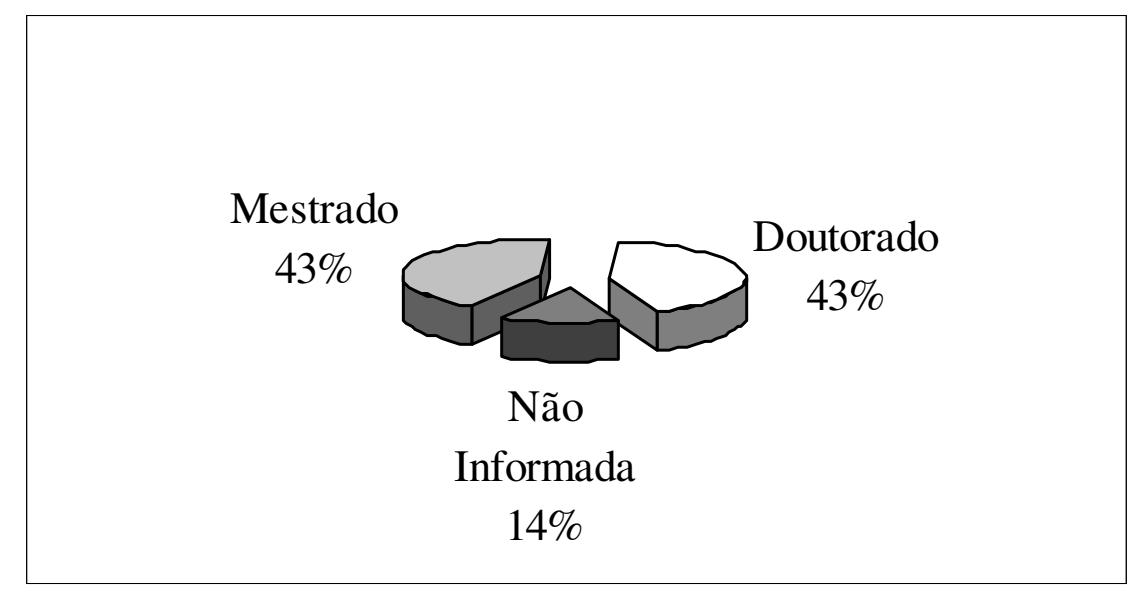

FIGURA 3 - Titulação dos autores.

Como podemos observar na Figura 3, há um equilibro no que se refere à titulação, entre doutores e mestres. A produção científica analisada no período de 1990 a 2005 é uma literatura produzida, em sua maioria, na academia, por docentes com título de mestres e doutores; fato esse peculiar, isto é, pesquisar e publicar os resultados das pesquisas faz parte das atividades do magistério de nível superior.

No contexto deste estudo, os temas, objeto de estudo dos artigos, foram classificados em dois grupos, isto é, teóricos e exploratórios (TAB. 6). Os estudos classificados na categoria de teóricos apresentam uma teorização, já os estudos exploratórios compreendem os de natureza quantitativo-descritivo, sem que haja uma necessidade de grande teorização.

Dos 21 artigos, 52\% foram classificados como exploratórios e $48 \%$ como de natureza teórica. Esse fato vem corroborar com a observação de que a pesquisa em ciência da informação é de natureza aplicada. Embora os estudos bibliométricos tenham esse caráter, não significa que estudos teóricos não devam ser realizados, muito pelo contrário, devem ser efetuados a fim de sedimentar o campo epistemológico da bibliometria.

TABELA 6 - Tipologia dos Estudos X Titulação

\begin{tabular}{l|c|c|c|c|c|c}
\hline \multirow{2}{*}{ Temas } & \multirow{2}{*}{ Quantidade } & \multirow{2}{*}{$\%$} & \multicolumn{4}{c}{ ESTUDO } \\
\cline { 4 - 7 } & & & Teórico & $\%$ & Exploratório & $\%$ \\
\hline Bibliometria & 9 & 42,9 & 7 & 70 & 2 & 18,18 \\
\hline Lei de Bradford & 2 & 9,5 & 1 & 10 & 1 & 9,09 \\
\hline Análise de Citação & 8 & 38,1 & 1 & 10 & 7 & 63,64 \\
\hline Obsolescência & 2 & 9,5 & 1 & 10 & 1 & 9,09 \\
\hline Total & 21 & 100 & 10 & 100 & 11 & 100,00 \\
\hline
\end{tabular}

A partir dos cruzamentos dos dados das Tabelas 4 e 5, foi possível identificar a classificação dos estudos e a titulação dos autores principais, resultando na TAB. 6. Assim, 50\% dos autores com título de doutor escreveram artigos de cunho mais teórico do que os dos mestres, que 
desenvolveram estudos de caráter exploratório com uma freqüência relativa de $45,45 \%$.

A fim de verificar a existência de associação entre as variáveis tipo de estudo e titulação dos autores dos artigos, efetuamos o teste de significância, levando em consideração as observações em que os autores declaram suas respectivas titulações, sendo que dos 21 artigos apenas 18 informaram (TAB 6A). Sendo assim, passamos a analisar a existência ou não de associação entre tipo de estudo e titulação, utilizando um nível de significância de 5\%, sito é,

TABELA 6A - Tipologia dos Estudos X Titulação

\begin{tabular}{l|c|c|c}
\hline \multirow{2}{*}{ Titulação } & \multicolumn{2}{|c|}{ Estudo } & \multirow{2}{*}{ Total } \\
\cline { 2 - 3 } & Teórico & Prático & \\
\hline \multirow{2}{*}{ Mestrado } & 4 & 5 & 9 \\
& $44.4 \%$ & $55.6 \%$ & $100.0 \%$ \\
\hline \multirow{2}{*}{ Doutorado } & 5 & 4 & 9 \\
& $55.6 \%$ & $44.4 \%$ & $100.0 \%$ \\
\hline Total & 9 & 9 & 18 \\
& $50.0 \%$ & $50.0 \%$ & $100.0 \%$ \\
\hline
\end{tabular}

Examinando descritivamente a TAB. 6A, pode-se verificar que existe uma similaridade entre os estudos feitos pelos autores independentes da titulação, ou seja, não existe associação entre essas duas variáveis. Para a verificação da existência ou não dessa evidência de associação, foi feito o teste de Fischer que forneceu um p-valor igual a um, ou seja, muito maior do que um nível de significância, indicando assim uma diferença estatisticamente não significativa, isto é, que não existe nenhum tipo de associação entre a tipologia do estudo e a titulação do autor.

TABELA 7 - Temática dos Artigos em Bibliometria X Tipologia do Estudo

\begin{tabular}{l|c|c|c}
\hline \multirow{2}{*}{ Temas } & \multirow{2}{*}{ Quantidade } & \multicolumn{2}{c}{ Estudo } \\
\cline { 3 - 4 } & & Teórico & Exploratório \\
\hline Bibliometria & 9 & 7 & 2 \\
$(70 \%)$ & $(18,18 \%)$ \\
\hline \multirow{2}{*}{ Lei de Bradford } & 2 & 1 & 1 \\
& $(9,5 \%)$ & $(10 \%)$ & $(9,095)$ \\
\hline \multirow{2}{*}{ Análise de Citação } & 8 & 1 & 7 \\
& $(38,1 \%)$ & $(10 \%)$ & $(63,64)$ \\
\hline \multirow{2}{*}{ Obsolescência } & 2 & 1 & 1 \\
\hline \multirow{2}{*}{ Total } & $(9,5 \%)$ & $(10 \%)$ & $(9,09)$ \\
\hline
\end{tabular}

Dos 21 artigos publicados no período de 1990 a 2005, foram identificados cinco temas de maior preocupação em estudos, quer sejam eles teóricos ou exploratórios (Tabela 7). A bibliometria como objeto de estudo correspondeu a 42,9\% dos estudos, embora alguns artigos apenas fizessem uma menção sobre a importância de estudos dessa natureza, correlacionando, por exemplo, com a gestão da informação e estudos na 
área de ontologias, demonstrando, assim, a intercessão dos estudos bibliométricos em outros campos de estudos, evidenciando a natureza interdisciplinar da bibliometria. Entretanto, a concentração maior dos estudos aponta para a análise de citação, com 38,1\% dos trabalhos, e observa-se também que essa modalidade de estudo bibliométrico foi responsável por 63,64 dos estudos exploratórios.

$\mathrm{Na}$ TAB. 7 pode-se observar descritivamente uma leve evidência de associação entre o tipo de estudo e o tema dos artigos, principalmente entre os temas abordados de bibliometria e análise de citação. Utilizando os testes da razão de probabilidade e de associação linear, ambos com hipóteses de confirmar a associação entre duas varáveis, obtivemos respectivamente $p$-valores iguais a 0,04 e 0,03. Como os valores obtidos são menores do que o nível de significância, logo se rejeita a hipótese de que as variáveis são independentes; ou seja, existe uma diferença estatisticamente significativa, indicando assim uma associação entre o tipo de estudo e a temática dos artigos.

É valido ressaltar que estudos envolvendo a análise de citação vêm merecendo uma atenção maior nas últimas décadas do século $X X$, sendo muito utilizados internacionalmente, uma vez que o Institut for Scientific Information/ISI (com sede nos Estados Unidos) disponibiliza uma base de dados multidisciplinar que permite várias pesquisas utilizando essa modalidade de estudo bibliométrico.

A Lei de Bradford foi objeto de estudos de $9.5 \%$ dos artigos. Observa Gato e colaboradores, (2004, p. 85) que ela é "uma das leis e técnicas da bibliometria que, embora concebida para analisar a produtividade de periódicos científicos, tem sido empregada em outras abordagens com a finalidade de obter indicadores para diversas ações de gerenciamento da informação". Vale ressaltar que 9.5\% dos estudos tiveram como objetivo a obsolescência da literatura em uma determinada área.

No estudo de Urbirazagástegui Alavarado (1984), que abrangeu o período de 1972 a 1983 (portanto o início dos estudos bibliométricos no Brasil), a temática da Lei de Bradford obteve uma presença acentuada na população utilizada pelo autor. Já para os estudos envolvendo a análise de citações, a freqüência de trabalhos permaneceu constante, isto é, em número de oito. Embora o citado estudo não possa ser tomado como referencial, uma vez que a diversidade das fontes consultadas foi bem superior à população utilizada neste estudo, podemos, no entanto, acompanhar a evolução dos temas que são objeto de estudo na contemporaneidade, no que tange ao Brasil. 


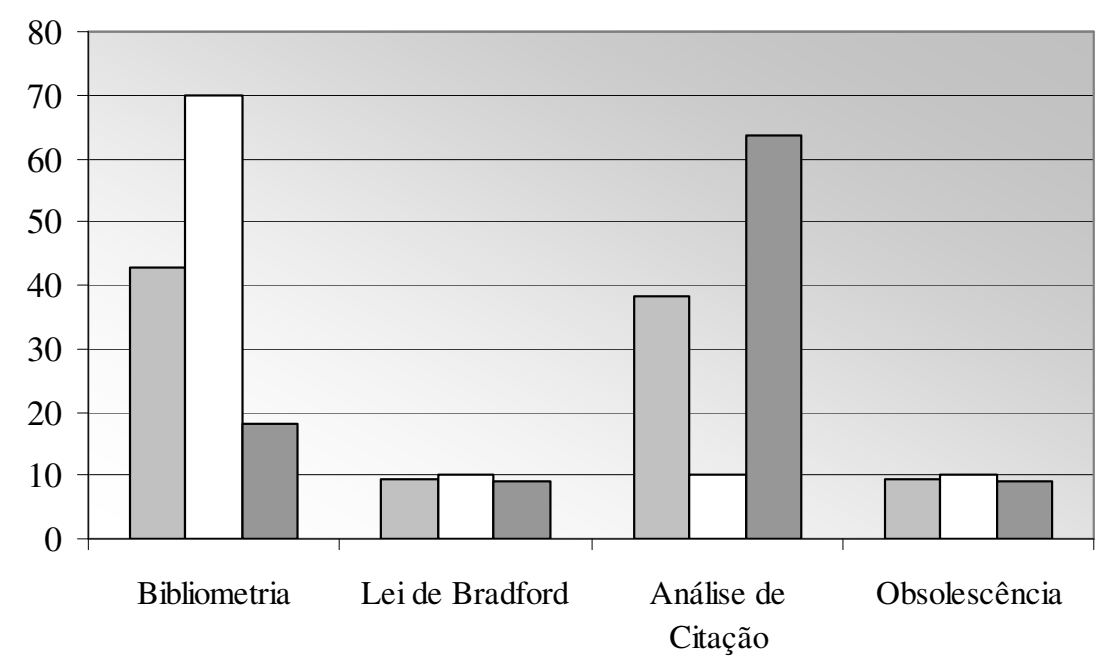

$\square \mathrm{N}^{\mathrm{o}}$ de Artigos $\square$ Estudo Teórico $\square$ Estudo Exploratório

FIGURA 5 - Temática dos artigos e tipos de estudos (\%).

A Figura 5 permite um novo cruzamento dos dados, proporcionando uma melhor visualização no que tange à temática dos artigos e ao tipo de estudo desenvolvido pelos autores. Assim, 70\% dos estudos teóricos referem-se à bibliometria, enfatizando, desde modo, um aspecto de sua aplicação, como já foi citado anteriormente. Já os estudos de análise de citação, obtendo uma freqüência relativa da ordem de $63,64 \%$ são de natureza exploratória. A distribuição dos temas envolvendo a Lei de Bradfrod e estudos de obsolescência da informação apresentaram-se sem grandes alterações.

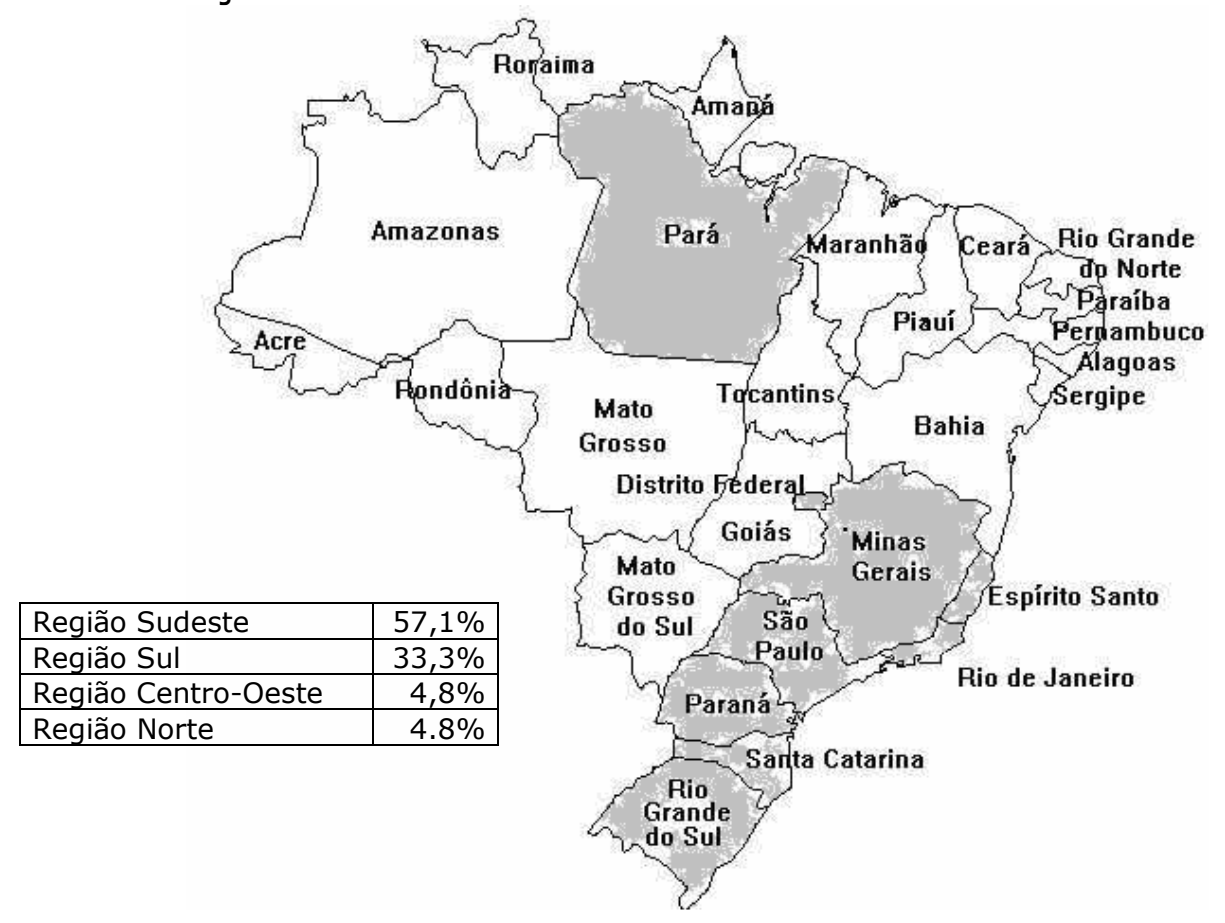

Figura 6 - Mapeamento da produção científica em bibliometria (19902005). 
Mapeando a produção científica em bibliometria de cidades do Brasil, pode-se observar, pela Figura 6 , que há uma concentração nas seguintes localidades: Brasília (Região Centro-Oeste) e Belém (Região Norte), com freqüência relativa de 4,8\% artigos; Santa Catarina, Itajaí, Florianópolis, Curitiba e Porto Alegre (Região Sul) com 33,3\%. A maior concentração de trabalhos, $57,1 \%$ do total geral da produção, está nos municípios de São Paulo, Campinas, Rio de Janeiro, Belo Horizonte e Vitória (Região Sudeste). No período estudado não foi encontrado nenhum artigo publicado na região Nordeste. É oportuno ressaltar que na região Sudeste concentra-se o maior número de programas de pós-graduação em ciência da informação do país, sede das instituições nas quais os autores dos artigos têm vínculo profissional.

TABELA 8 - Autoria dos artigos e sua produção anual

\begin{tabular}{|c|c|c|c|c|c|c|c|c|c|c|c|c|}
\hline \multirow{2}{*}{ Autores } & \multicolumn{11}{|c|}{ Ano } & \multirow{2}{*}{ Total } \\
\hline & 1990 & 1991 & 1995 & 1997 & 1998 & 2000 & 2001 & 2002 & 2003 & 2004 & 2005 & \\
\hline ALVARENGA, L & & & & & 1 & & & & & & & 1 \\
\hline BORGES, PCR & & & & & & & & 1 & & & & 1 \\
\hline BUFREM, LS & & & & & & & & & & & 1 & 1 \\
\hline COUTINHO, E & & 1 & & & & & & & & & & 1 \\
\hline FIUZA, MM & & & 1 & & & & & & & & & 1 \\
\hline FORESTI, NAB & 1 & & & & & & & & & & & 1 \\
\hline FREITAS, MHA & & & & 1 & & & & & & & & 1 \\
\hline GATO, RF & & & & & & & & & & 1 & & 1 \\
\hline MOSTAFA, SP & & & & & & & & & 2 & & & 2 \\
\hline MUGNAINI I, R & & & & & & & & & 1 & 1 & & 2 \\
\hline NASCIMENTO, MJ & & & & & & 1 & & & & & & 1 \\
\hline NORONHA, D & & & & & 1 & & & & & & & 1 \\
\hline OBERHOFER, CMA & & 1 & & & & & & & & & & 1 \\
\hline OLIVEIRA, E & & & & & & & & & & 1 & & 1 \\
\hline PACHECO, RCS & & & & & & & 1 & & & & & 1 \\
\hline PITTELLA, MC & & 1 & & & & & & & & & & 1 \\
\hline SANTOS, RNM & & & & & & & & & 1 & & & 1 \\
\hline STREHL, L & & & & & & & & & & & 1 & 1 \\
\hline VANTI, NAP & & & & & & & & 1 & & & & 1 \\
\hline Total & 1 & 3 & 1 & 1 & 2 & 1 & 1 & 2 & 4 & 3 & 2 & 21 \\
\hline
\end{tabular}

Na TAB. 8 encontra-se a distribuição de autores e sua produção no período de 1990 a 2005. Foram registrados 19 autores (considerou-se apenas os autores principais) que no conjunto foram responsáveis por 19 artigos. Deste universo, apenas dois - 10,53\%, Mostafa e Muganaini, publicaram mais de um artigo; portanto a incidência de autores com apenas um único trabalho $(89,47 \%)$ é predominante. Isso nos leva a inferir que no período de estudo não há grandes produtores de estudos bibliométricos. 


\section{Conclusão}

A apreciação dos dados apresentados nos fornece um conjunto de indicadores da produção científica em bibliometria, publicada em quatro periódicos nacionais, editados de 1990 a 2005.

A população pesquisada foi de 21 artigos assinados por 19 autores nacionais pertencentes a instituições sediadas no Brasil, concentradas em sua maioria na região sudeste do país. Região esta que tem o maior número de cursos de pós-graduação em ciência da informação, sendo ainda a região com o maior índice de produtividade, 57, $1 \%$, uma vez que há uma predominância de autores docentes vinculados a instituições de ensino. No entanto, não temos grandes produtores em bibliometria no Brasil. Deste universo, ou seja, dos 19 autores, apenas dois publicaram mais de um artigo, que em conjunto somaram quatro; os demais autores contribuíram com um artigo, predominando a autoria única.

Comparar a produção no período estudado de 2000 a 2005 em bibliometria vêm fazendo-se presente ano a ano; o mesmo não ocorreu na década de 90. A análise de citação, modalidade de estudo bibliométrico, foi mais freqüente nos estudos; certamente esse tipo de trabalho impulsionará os estudos nos próximos anos, uma vez que os índices de citação existentes hoje possibilitam inúmeros estudos.

Para que os estudos bibliométricos possam ser mais efetuados, fazse necessário introduzir na graduação temas ligados à bibliometria. Uma boa ocasião seria introduzi-los na disciplina Formação e Desenvolvimento de Coleções, no tocante à atividade de avaliação de coleções, utilizando a Lei de Bradford ou a análise de citação, fortes elementos para a tomada de decisão na seleção ou no desbastamento.

Os indicadores apontados neste estudo apresentam um quadro bem atual dos estudos bibliométricos desenvolvidos no Brasil. No entanto não esgota a possibilidade de novos estudos, incluindo outras fontes de informação, como fez Urbirazagástegui Alavarado (1984), que poderá apresentar um novo panorama da bibliometria desenvolvida no Brasil.

\section{Referências}

ALVES-MAZZOTTI, A. J.; GEWANDSZNAJDER, F. O método nas ciências naturais e sociais: pesquisa quantitativa e qualitativa. São Paulo: Pioneira, 2001.

BRASIL. Conselho Nacional de Desenvolvimento Cientifico e Tecnológico. Plataforma Lattes. Disponível em: <http://www.lattes.ufba.br>. Acesso em: 12 de setembro de 2006.

BUFREM. L.; PRATES, Y. O saber científico registrado e as práticas de mensuração da informação. Ciência da Informação, Brasília, v. 34, n. 2, p. 9-25, maio/ago. 2005.

CARRIZO SAINERO, G. Hacia un concepto de bibliometria. Revista de Investigación Iberoamericana en Ciencia de la Información y 
Documentación, v. 1, n. 2, jul/dec. 2000. Disponível em: <http://www.ucm.es/info/multidoc/publicaciones/journal/>. Acesso em 23 mar. 2005.

FONSECA, E. N.(Org). Bibliometria: teoria e prática. São Paulo: Editora da Universidade de São Paulo, 1986.

GATO, R. F. et al. Gestão da informação na Embrapa Amazônia Oriental: uso relativo versus uso efetivo da literatura técnico-científica agropecuária periódica - 1990-1999. Ciência da Informação, Brasília, v. 33, n. 2, p. 8390, maio/ago. 2004.

GREGORIO CHAVIANO, O. Algunas consideraciones teórico-conceptuales sobre lãs disciplinas métricas. ACIMED, Havana, v. 12, n. 5, set./out. 2004.

LAVILLE; C.; DIONNE, J. A construção do saber: manual de metodologia da pesquisa em ciências humanas. Porto Alegre: Arte Médica Sul Ltda; Belo Horizonte: Editora, UFMG, 1999.

MEADOWS, A. J. A comunicação científica. Brasília: Briquete de Lemos/Livros, 1999.

MUELleR, S. P. M.; PECEGueiro, C. M. P. de A. O periódico Ciência da Informação na década de 90: um retrato de área refletido em seus artigos. Ciência da Informação, Brasília, v. 30, n. 2, p. 47-63, maio/ago. 2001.

MUGNAINI, R.; JANNUZZI, P.; QUONIAM, L. Indicadores bibliométricos da produção científica brasileira: uma análise a partir da base Pascal. Ciência da Informação, Brasília, v. 33, n. 2, p. 123-131, maio/ago. 2004.

PÉREZ MATOS, N. E. La bibliografia, bibliometría y las ciencias afines. ACIMED, Habana, v. 10, n. 3, maio-jun, 2002. Disponível em: <http://bvs.sld.cu/revistas/aci/vol10_3_02/Aci012002.htm>. Acesso em: 6 de maio de 2006.

PINHEIRO, L. V. R. Infra-estrutura de pesquisa em ciência da informação no Brasil. R. Bibliotecon. Brasília, v. 23/24, n. 3, p. 367-390, especial 1999/2000.

PIVETTA, M. O salto quântico da ciência. Revista Pesquisa, São Paulo, v. 10, jun. 2004. Disponível em: <http://www.revistapesquisa.fapesp.br>. Acesso em: 15 jul. 2004

SANCHO, R. Indicadores Bibliometricos Utilizados em la Evaluacion de la Ciência y la Tecnologia: revision bibliográfica. Revista Espanola de Documentacion Cientifica, Madrid, v. 13, n. 3-4, p. 842-865, 1990.

SANTOS, R. N. M. dos. Indicadores estratégicos em ciência e tecnologia: refletindo a sua prática como dispositivo de inclusão/exclusão. Transinformação, Campinas, v. 129-140, set./dez. 2003, (Edição Especial). 
SOLLA PRICE, D. J. de. O desenvolvimento da ciência: análise histórica, filosófica, sociológica e econômica. Rio de Janeiro: Livros Técnicos e Científicos, 1976.

URBIRAZAGÁSTEGUI ALAVARADO, R. A bibliometria no Brasil. Ciência da Informação, Brasília, v. 13, n. 2, p. 91-105, jul.dez. 1984.

\section{Apêndice A - Palavras-Chave para Seleção dos Artigos}

1. Análise bibliometrica

2. Análise de citação

3. Bibibliometria

4. Indicadores bibliométricos

5. Lei de Bradford

6. Lei de Lotka

7. Lei de Zipf.

8. Obsolescência 